\title{
The Relationship of Accident Risk Factors with Traffic Road Safety: A Study on Commercial Mini-Bus Accident in Nigeria.
}

\author{
Engr. Dr. A.O Oke ${ }^{1}$, Engr. Dr. Arowolo M.O ${ }^{2}$, Engr. Oyebamiji B.A ${ }^{3}$ \\ and A.O Oloyede \\ ${ }^{1}$ (Department of Mechanical Engineering, Osun State College of Technology, Esa - Oke, Nigeria) \\ ${ }_{2}^{2}$ (Department of Mechatronics Engineering, Osun State College of Technology, Esa - Oke, Nigeria) \\ ${ }_{3}^{3}$ (Department of Mechanical Engineering, Osun State College of Technology, Esa - Oke, Nigeria) \\ ${ }^{4}$ (Registry Department, Osun State College of Technology, Esa - Oke, Nigeria)
}

\begin{abstract}
The main purpose of this study is to identify the relationship between Human Factors, Mechanical/Vehicle Factors, Environmental/Road Factors and Road Safety. Ten traffic agent officers (Comprising Road Safety Corps, Road Safety Marshal, State Security Service Officers, Police Traffic officers and National Union of Road Transport Workers (NURTW) officers) were selected as a sample, survey questionnaire was used for data collection for a period of two months, majority of the officers (52.7\%) were in the age category of 36 to 44 years old, with (96.7\%) having driving education with training. There were significant relationship between Human Factors, Mechanical/Vehicle Factors $(r=0.619, \quad p<0.01)$ and Environmental/Road Factors $(r=0.579, p<0.01)$. Result from multiple regression analysis shows that $62.7 \%$ can be explaining by Human Factors, Environmental Factors and Mechanical/vehicle Factors contribution to mini bus traffic accident with significant relationship between Human Factors, Environmental Factors ( $r=0.619$, $p<0.01)$ and Mechanical Factors $(r=0.579, p<0.01)$ with accident occurrence. It is therefore recommended that commercial transport company needs to do a lot of human factors preventive measure among bus drivers by conducting training and risk perception seminar from time to time.
\end{abstract}

Keywords: Bus accident, Environmental Factors, Human Factors, Road Safety.

\section{Introduction}

The driver is a major and critical component of the traffic system, many attempts have been previously made to estimate the importance of the driver as the major cause of accident [1], it has been estimated that road user factors are the major contributory factors of road accident, while speeding behaviour of bus drivers is chosen as an indication of good driver management. According to Osman et al (2009)[2]. Drivers who adhere to speed limits will always be aware of limitations on the road, a good driving behaviour and adherence to traffic rules will definitely reduce the probability of being involved in accidents. With more trained drivers, the accident rate is expected to drop and importantly, the severity of accidents is expected to decline, especially in accidents involving buses which usually claim many lives. Commercial buses are considered a major mode of transportation in most developing countries. In Malaysia, they are privately owned and operated generally by individuals and transportation firms as contain in Nailul et al (2011) [3] in their work on factors of fatigue and bus accident which stated that driver fatigue is a safety issue of general concern to the bus transportation industries which may be cause by a combination of factors including inadequate rest or disrupted sleep, displaced biological rhythms, excessive physical activity or mental and cognitive work as well as stress. Commercial bus safety is a major concern both in developing and developed countries even in US and Europe where, although bus transport is considered a safe mode of transport, yet the number of injuries and fatalities is still very high [4], In the U.S between 1999 and 2005 about 63,000 buses were involved in traffic accidents that resulted in 14,000 injuries and 325 fatalities. Every year [5] and in Europe, about 20,000 buses were implicated in traffic collisions that led to 30,000 injuries and 150 fatalities every year. Commercial bus safety is also a concern in Demark, where in 2000 the Danish Commission on Road Safety prepared a national plan for road safety covering the period between 2001 and 2012 with the aim of minimizing road accidents. The review of road transport policy was carried out in India and it was observed that there was a steady increase in traffic fatalities in spite of the presence of traffic rules, regulations and legislative systems all over the country and stated that one possible reason for this is the increasing number of vehicles on the road [6], [7]. Elke Hermans et al,2008 [8] believe that the higher accident rate among commercial buses result from their operating characteristics as a result of multiple driving task and distractions from some passenger like the rate of loading and unloading particularly in urban areas. The bus driver out of curiosity and pressure to increase profit and continuously fears the loss of his job, the driver therefore is compelled to work long hours and therefore more stressful as compared to other types of driving. 
This study has provided valuable insights regarding commercial bus traffic accident under three major identified driving factors as driving hazard, driving task and driving risk.

\section{Identifications Of Risk Factors}

\section{DRIVING RISK}

Driving risk is the subjective judgment that people make about the characteristics and severity of a risk driving especially for young novice drivers are at a significantly higher risk of having a fatal vehicle crash than experienced drivers. According to Rosoff \& John 2009 [9], one of the main causes of accident is that novice drivers lack risk perception skills, they have not developed the ability to efficiently perceive or predict risks while driving. According to risk factors influencing crash severity seven factors of driving risk were identified as: human tolerance factors, inappropriate or excessive speed, seat-belts and child restraints not used, crashhelmets not worn by users of two-wheeled vehicles, roadside objects not crash-protective, insufficient vehicle crash protection for occupants and for those hit by vehicles and presence of alcohol and other drugs [9].

\section{Driving Distraction}

Distracted driving is the act of driving while engaged in some other activities like eating snacks, texting, talking on phone or to passenger or reading map that take the driver's attention away on the road. All distractions compromise the safety of the driver, the passenger's bystanders and those in other vehicles [8]. United States Department of Transportation says texting while driving creates a crash risk 23 times higher than driving while not distracted. Inspite of this, statistics shows that more than $37 \%$ of drivers have admitted to sending or receiving text messages while driving and $18 \%$ admit doing so regularly. According to U.S. Department of Transportation, 2009 [13] on driver's distraction on commercial vehicle five major categories of human direct causes were identified: recognition errors, decision errors, performance errors, critical nonperformance errors, and non-accident/intentional involvement. In addition, five specific human causes were identified: improper lookout (18-23 percent), excessive speed (8-17 percent), inattention (10-15 percent), improper evasive action (5-13 percent), and internal distraction (6-9 percent). It can be seen that two of the five specific human causes were related to inattention and distraction, indicating their prevalence during vehicle crashes.

\section{Environmental/Road Factors and Distractions}

According to European Transport Safety Council (2001)[11], there are possible countermeasures for minimising distractions which include (1). Research, which require a carefully designed study of the prevalence of driver's involvement in distracting activities within the vehicle, the research can be extended to identification of factors that influence driver's willingness to engage in potential distracting tasks while driving. (2). Education and training, necessary safety awareness and training should be conducted with drivers and highlight the most ergonomic and least distracting methods for the use of in-vehicle facilities. (3). Legislation and enforcement, there should be a review of the existing legislation, new legislation created to limit driver's exposure to and discourage drivers from engaging in activities which have the potential to distract them. (4). Vehicle design, studies shows that the most effective way to minimize technology-based distraction is to design the Human Machine Interface (HMI) ergonomically. (5). Licensing, handbooks for novice drivers and probationary drivers should draw attention to the potential risks associated with engaging in distracting activities within the vehicle [13]. Knowledge test as well should include items pertaining to the relative risks associated with engaging in these activities.

\section{Methodology}

The data required for this study was collected from 10 traffic agent officers (Comprising Road Safety Corps, Road Safety Marshal, State Security Service Officers, Police Traffic officers and National Union of Road Transport Workers (NURTW) officers). They were selected as a sample and survey questionnaire was used for data collection for a period of two months in two consecutive periods using a Delphi stated technique.

\section{Modeling Approach Used}

The utility (V) of each of the four primary alternatives (i) in the Delphi experiment is for each individual $\mathrm{n}$ specified as a linear in-parameters function of the relevant SP attributes together with interactions amongst these attributes and also dummy variable interactions relating to the characteristics of the sampled individuals and the problem context. Formally:

Vin $=\beta$ xin $+\gamma$ zin $+\delta$ cnxin $+\theta$ cxin where xin is a vector of SP attributes, zin is a vector of interactions of SP attributes, $\mathrm{Cn}$ is a vector of dummy variables relating to individual $\mathrm{n}, \mathrm{c}$ is a vector of dummy variables relating to the problem context, and $\beta, \gamma, \delta, \theta$ are vectors of parameters to be estimated. The $\beta$ therefore represents the main effect of the variable in question. The extent to which this effect varies according to some 
other variable, an individual or a problem context is represented by $\gamma, \delta$ and $\theta$, respectively. The safety threshold or notional sixth alternative was specified simply as an alternative-specific constant. We have also generalised the linear-in-parameters form to allow for non-linearities in response by using piecewise estimation. A dummy variable is specified for each of $n-1$ levels of a variable with $n$ categories. The coefficient estimates indicate the effect upon utility of the relevant categories relative to the arbitrarily omitted (base) category. The model can be estimated using ALOGIT [13] and it's jack-knife procedure accounted for the repeated observations per respondent which cannot be quantified

Descriptive statistics (frequency and percentage) was used to describe the demographics factors (Gender, Age, Marital status, Driver education, Accident history, Nature of accident, driving experience, driving per week, Vehicle age and Types of journey). Inferential statistics (Pearson Product Moment Correlation Coefficient and Multiple Regression Analysis) was equally used for data analysis..

\section{Analysis Of Results}

\section{Pearson Product Moment Correlation Coefficient's Results}

There were significant relationship between driving hazard, driving distraction $(\mathrm{r}=0.619, \mathrm{p}<0.01)$ and driving risk $(\mathrm{r}=0.579, \mathrm{p}<0.01)$ in the same manner distraction correlate significantly with driving hazard and driving risk $(\mathrm{r}=0.631, \mathrm{p}<0.01)$. This is because many identified hazard on the road such as hazards when driving through business areas, identifying hazards when driving through road works, hazards when driving through school zones, hazards identification when sharing the road with other road users, hazards when driving through suburban streets, and hazards when driving as night is approaching all these result into driving distraction and risk on the part of the driver. In addition, the findings revealed that there was also a significant relationship between driving risk and traffic accident $(r=0.259, \mathrm{p}<0.01)$.

Multiple Regression Analysis Results

Table 2. Model Summary of Dominant Factors (Driver Hazard, Driver Distraction and Driver Risk)

Model Summary

\begin{tabular}{|c|c|c|c|c|c|c|c|c|c|}
\hline \multirow[b]{2}{*}{ Model } & \multirow[b]{2}{*}{$\mathrm{R}$} & \multirow[b]{2}{*}{ R Square } & \multirow[b]{2}{*}{$\begin{array}{c}\text { Adjusted R } \\
\text { Square } \\
\end{array}$} & \multirow[b]{2}{*}{$\begin{array}{l}\text { Std. Error of } \\
\text { the Estimate }\end{array}$} & \multicolumn{5}{|c|}{ Change Statistics } \\
\hline & & & & & $\begin{array}{c}\text { R Square } \\
\text { Change }\end{array}$ & F Change & df1 & df 2 & Sig. F Change \\
\hline 1 & $.455^{\mathrm{a}}$ & .207 & .180 & .90566662 & .207 & 7.531 & 5 & 144 & .000 \\
\hline
\end{tabular}

a. Predictors: (Constant), Road Factors, Driver Factors, Vehicle Factors, Driver Task, Driver Risk

Table 3.Coefficient of Dominant Factors (Driver Hazard, Driver Task and Driver Risk) Affecting

Commercial Mini - Bus Accident.

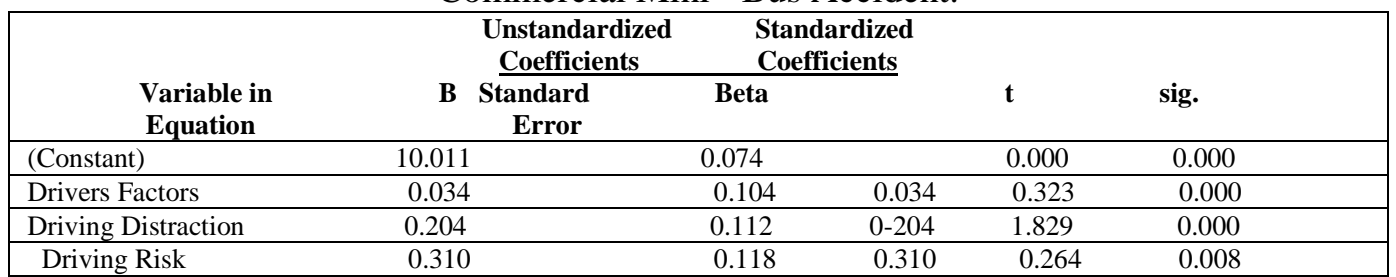

Table 3 showed that driving hazard, driving distraction and driving risk were the dominant factors that contribute to bus accident. Therefore $20.7 \%$ can be explaining by driving hazard, driving distraction and driving risk variables in the table above. However, driving risk made the strongest unique contribution as it produced the highest beta coefficient result (beta $=0.310$ ). Driving risk and traffic accident could be very serious among commercial bus accident occurrence. According to Carsten (2007) [13] one of the main causes of accident is that novice drivers lack risk perception skills, they have not developed the ability to efficiently perceive or predict risks while driving. Thus a good risk perception among commercial driver will reduced the level of traffic accident among commercial bus drivers.

\section{Measurement and Structural Model Assessment}

Model assessment (Figure 4.1) can be achieved by the measurement and structural working model analysis, running the maximum likelihood estimate for the model revealed significant Chi - square statistics where $\chi^{2}=201.453$ with 84 degree of freedom, the model fit indices for the total sample in the initial CFA run produced the following indices: $\mathrm{GFI}=.903, \mathrm{CFI}=.918$ and RMSEA $=.091, \mathrm{CMIN} / \mathrm{DF}=2.233$. The identified risk factors measure traffic accident more than $90 \%$ according to the measurement model prediction. 


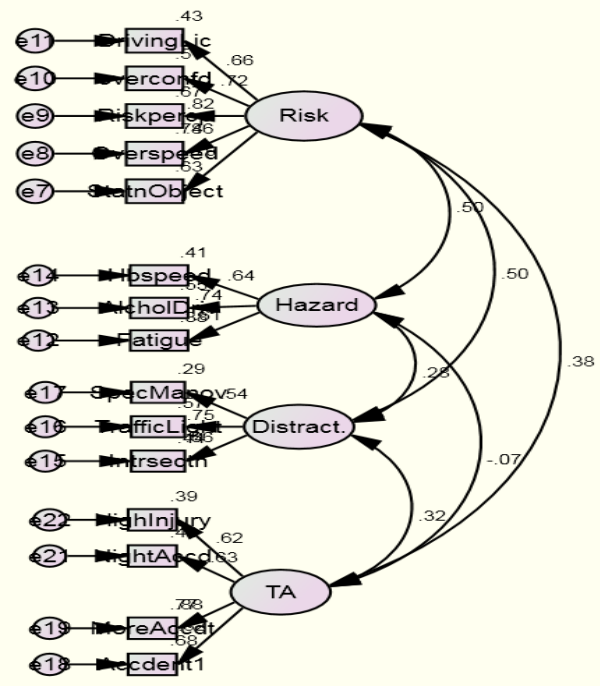

Figure 4.1 Measurement Model of Identified Accident Risk factors by the Experts

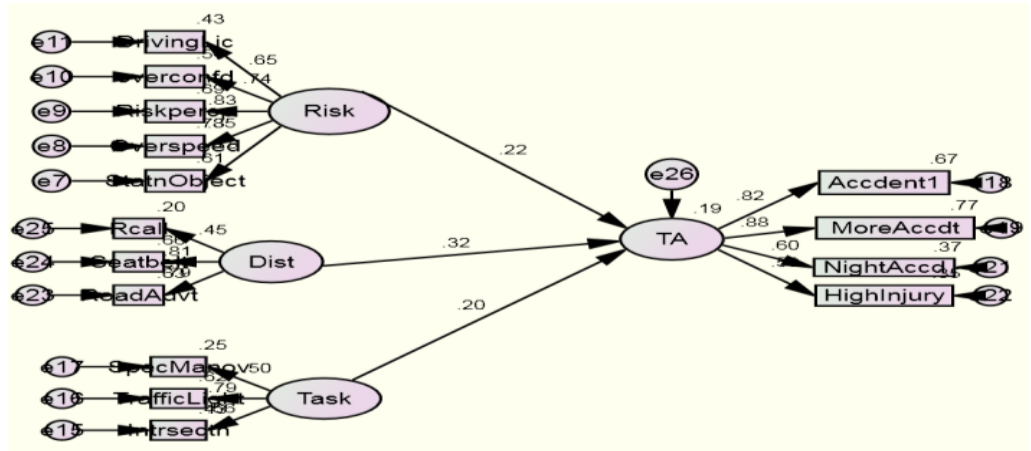

Figure 4.2 Structural Equation Model of Identified Accident Risk factors by the Experts

Structurally Figure 4.2 shows that the three identified risk factors predict traffic accident well (82\%, $88 \%$ and $60 \%$ for risk, distraction and task respectively). The value 0.50 is the correlation between hazard and risk and between risk and distraction 0.24 is the correlation between task and hazard while 0.53 is the correlation between hazard and risk. Distraction correlate with traffic accident by 0.32 while risk correlate with traffic accident by 0.38 .

\section{Conclusion}

The results reveals that traffic agent officers (Comprising Road Safety Corps, Road Safety Marshal, State Security Service Officers, Police Traffic officers and National Union of Road Transport Workers (NURTW) officers) play an important role in the prevention of commercial mini- bus traffic accidents. Hazard preventive measure among drivers is highly essential by conducting training and retraining regularly. Driver's factor has a big influence on the rate of accident; statistics obtain from the Road Safety Corps database for 2012 - 2016 shows an increase in total number of road accident on yearly bases in which buses claim more lives due to high numbers of passengers on board.

This study has provided valuable insights regarding traffic accident under three major identified driving factors (driving hazard, driver is distraction and driving risk under Driver's factor) that influence commercial mini- bus traffic accident. This knowledge is important so as to reduce the rate of accident among commercial mini-bus drivers in Nigeria.

\section{Acknowledgements}

The authors wish to thank the Tertiary Education Trust Fund (TETfund), which supported this research, and the various traffic agencies that participated in the survey.

\section{References}

[1]. Behaviour, M. D., Union, E., \& Projects, I. (1993). Modelling Driver Behaviour in European Union and International Projects.

[2]. Mohd Rasid Osman, Rohayu Sarani, Zarir Hafiz Zulkipli, Noor Faradila Paiman, W. S. V. (2009). The Effect of Driver Management System According to SHE COP in Reducing Speed Violations. MIROS Publication, MRR 11/2009., 11. 
[3]. Dayang Nailul Munna Abang Abdullah and Ho Li Von, Factors of Fatigue and Bus accident, International Conference on Innovation, Management and Service, IPEDR vol.14 (2011). Singapore.

[4]. Assum, T., \& Sørensen, M. (2010). Safety Performance Indicator for alcohol in road accidents--international comparison, validity and data quality. Accident; analysis and prevention, 42(2), 595-603. doi:10.1016/j.aap.2009.10.005

[5]. Amditis, A., Pagle, K., Joshi, S., Bekiaris, E., (2010). Driver-vehicle-environment monitoring for on board driver support systems. Use cases and validation. Applied Ergonomics 41 (2),

[6]. Casucci, M., Marchitto, M., Cacciabue, P.C., (2010). A numerical tool for reproducing driver behaviour: Experiments and predictive simulations. Applied Ergonomics.

[7]. Engstro“M, J., Hollnagel, E., (2007). A general conceptual framework for modeling behavioural effects of driver support functions. In: Cacciabue, P.C. (Ed.), Modelling Driver Behaviour in Automotive Environments. Springer-Verlag,London

[8]. Elke Hermans, Filip Van den Bossche, Geert Wets (2008). Combining road safety information in a performance index.

[9]. Rosoff, H., \& John, R. (2009). Risk Perception : Driving Factors Presentation Outline

[10]. Analysis of professional truck driver's task,2012.

[11]. European Transport Safety Council (2001). Transport safety performance indicators. European Transport Safety Council.

[12]. Cacciabue, P.C., Re, C., Macchi, L., (2007). Simple simulation of driver performance for prediction and design analysis. In: Cacciabue, P.C. (Ed.), Modelling Driver Behaviour in Automotive Environments. Springer-Verlag, London, UK.

[13]. Carsten, O., (2007). From driver models to modelling the driver: what do we really need to know about the driver? In: Cacciabue, P.C. (Ed.), Modelling Driver Behaviour in Automotive Environments. Springer, London.

[14]. European Commission (2005). Sustainable development indicators to monitor the implementation of the EU sustainable development strategy. Commission of the European Communities.

[15]. Hakkert A.S and V.Gitelman(Eds.)(2007). Road Safety Performance Indicators Manual Deliverable D3.8 of the FP6 project SafetyNet.

[16]. U.S. Department of Transportation. (2009). Driver distraction in commercial vehicle operations., (September,2009). 